\title{
FRICÇÕES, FISSURAS OU TRANSBORDAMENTO DE LINGUAGEM NAS ARTES?
}

\section{FRICTIONS, FISSURES OR LANGUAGE OVERFLOW IN ARTS?}

\author{
Thaís Gonçalves ${ }^{1}$
}

\begin{abstract}
Resumo: O que resta de uma linguagem artística quando os verbos de ação parecem sinalizar o desejo de não definir contornos para a produção em artes? Desconstruir, borrar fronteiras, subverter e esgarçar as lógicas, os conceitos, os corpos e a própria arte são palavras presentes no universo contemporâneo da produção artística em seus diferentes modos de expressão. Há autores de outras áreas, alheias às artes, como o espanhol Jorge Larrosa e o alemão Hans Ulrich Gumbrecht, cujas áreas de atuação são, respectivamente, educação e literatura, que enunciam, em contextos diferentes, um desejo de operar fora da linguagem. Os artistas plásticos brasileiros Lygia Clark e Hélio Oiticica desafiam, desde os anos 1960, as artes em sua linguagem ao proporem uma arte sem mediação. Seria uma arte fora da linguagem? Neste texto desejo me movimentar nessa questão para pensar o que faz variar e compor a linguagem quando sua natureza é a artística.
\end{abstract}

Palavras-chave: Linguagem artística; arte contemporânea; lógica da sensação.

Abstract: What is left of an artistic language when action verbs seem to signal the desire not to define contours for art production? Deconstructing, blurring boundaries, subverting and fraying logic, concepts, bodies and art itself are words present in the contemporary universe of artistic production in its different modes of expression. There are authors from other areas, outside the arts, such as the Spanish Jorge Larrosa and the German Hans Ulrich Gumbrecht, whose areas of expertise are, respectively, education and literature, which enunciate, in different contexts, a desire to operate outside language. Brazilian plastic artists Lygia Clark and Hélio Oiticica have been challenging, since the 1960s, the arts in its language by proposing an art without mediation. Would it be an art out of language? In this text I want to move on this question to think about what makes language vary and compose when its nature is artistic.

Keywords: Artistic language; contemporary art; logic of sensation.

Desconstruir, atravessar e borrar fronteiras, subverter e esgarçar as lógicas, os conceitos, os corpos, a arte. O que resta de uma linguagem artística quando os verbos de ação parecem sinalizar o desejo de não definir contornos para a produção em artes? São imperativos da contemporaneidade nas artes ou fricções que vitalizam o ato de criação na própria condição criadora? Operar dentro da linguagem ou fora dela? Eis uma questão que ecoa em mim desde a defesa da minha tese de doutorado em Dança e em Artes da Cena, em janeiro de 2018, realizada em regime de co-tutela, respectivamente junto à Universidade de Lisboa (ULisboa) e à Universidade Estadual de Campinas (UNICAMP).

Ao pesquisar sobre as sensações como mobilizadoras para a criação em dança e as relações de um certo modo de subverter a lógica dos corpos pela lógica das sensações, por mim relacionadas a um modo antropofágico de criação, me deparei com autores de contextos alheios às artes do corpo, de realidades distintas entre si, que enunciavam ser preciso expressar-se fora da linguagem e por um viés corporal e sensorial. O que me despertou curiosidade pois, de algum modo, o termo "linguagem" aplicado ao universo das artes me parecia um tanto descabido para

\footnotetext{
${ }^{1}$ Universidade Federal do Ceará, Fortaleza, CE, Brasil.
} 
a natureza inerente a esse campo de saberes em suas diferentes manifestações sejam visuais, cênicas, sonoras, sensoriais.

Meu movimento era de idas e vindas. Por um lado, o termo "linguagem" me soava tanto limitador quanto desafiador, por desdobrar-se na necessidade de se apreender certos códigos e, com eles, ser capaz de operar uma gramática para, enfim, tornar-se hábil a criar poeticamente. Nesse aspecto, é possível dizer que há, entre nós, analfabetos funcionais da arte, tanto do ponto de vista da apreciação como da própria produção artística. Sendo assim, seguiria válida a máxima das vanguardas modernistas e contemporâneas de que se o público não entende uma obra de arte é porque ele não tem conhecimento para tal, não foi exposto suficientemente a certos conteúdos e, portanto, não tem como fazer uma leitura apropriada das criações artísticas. Por outro lado, como explicar que certas criações artísticas, em seus mais diferentes formatos - espetáculos de grande público ou intimistas, instalações, intervenções, entre outros -, possam atingir um leigo em artes tão profundamente a ponto de mudar o seu modo de sentir, perceber e ver o mundo?

Será que é preciso ser alfabetizado nas linguagens das artes - dança, teatro, artes visuais, música - para ser atingido por uma criação artística quando ela se enuncia no mundo? O quanto os artistas são suficientemente alfabetizados para subverterem as lógicas dos corpos, das ideias, dos conceitos, do nosso modo de sentir, perceber e ver o mundo? Com essas indagações, convido o leitor deste texto para tatear, comigo, uma pergunta que a filósofa portuguesa Ana Godinho me fez na minha defesa de doutorado: será mesmo preciso que a arte opere fora da linguagem ou será que a linguagem das artes opera de outro modo e, portanto, seria próprio de sua natureza os movimentos de desconstruir, esgarçar, subverter para refazer, reorganizar, reposicionar a sua própria linguagem?

\section{Fora da linguagem?... Respirar}

Nas duas últimas décadas assisti com curiosidade um interesse cada vez maior da filosofia, da educação e da literatura pelo corpo. Essas áreas pareciam tratar das afecções dos corpos de um modo muito mais contundente e eficaz do que os "reles" artistas da cena. Por vezes, sentia que eu não estava habilitada para falar sobre a matéria relativa ao meu próprio ofício de formação profissional. Essa sensação era compartilhada por diversos colegas. Cheguei a ter uma proposta de comunicação recusada, recentemente, em um congresso sobre o gesto, muito embora eu propusesse uma discussão sobre o modo como o gesto estava sendo repensado por uma criadora em dança, nos termos dessa linguagem artística. Um tipo de recusa que percebo não se limitar a mim e nem a este contexto específico.

Possíveis ressentimentos à parte, o que de fato me despertou a atenção foi perceber que, de algum modo, era urgente falar do corpo e da arte em diferentes contextos, para além do campo artístico. Afinal, não é porque cada um de nós habita um corpo que o conhece em sua plenitude. Ele, o corpo, já não se constitui como uma evidência inquestionável, como diz o filósofo José Gil (2004), portanto nem como um sujeito suposto saber, ou ainda como um objeto/instrumento suposto saber.

$\mathrm{Na}$ filosofia, destaco alguns movimentos que me parecem interessantes no sentido de uma compreensão das afeções dos corpos. O filósofo francês Gilles Deleuze se aproximou do pintor Francis Bacon para extrair, dele, o que se tornou o título de seu livro Francis Bacon: a lógica da sensação (2007). Segundo o Deleuze, é preciso "pintar com as forças". José Gil fez uma importante contribuição para o campo da dança ao escrever Movimento total: o corpo e a dança (2004), onde dedicou-se a compreender de perto a criação de coreógrafos, tais como Yvonne Rainer e Steve Paxton. Artistas pós-modernos americanos, pertencentes a uma geração que efetivamente esgarçou o mais que pôde a noção do que é dança, portanto abrindo e desafiando à exaustão a constituição dessa arte como linguagem. 
Tal esgarçamento tem como importante referência a obra A fonte (1917) de Marcel Duchamp, o famoso urinol invertido que instaurou a recorrente e espinhosa pergunta: "o que é arte?". O momento histórico que se segue é de um aparente pessimismo, pois chega-se a falar no fim da arte. Período entre e pós-grandes guerras mundiais no século XX, diversos autores apontam para o fim das grandes narrativas com projetos delineados de antemão para um futuro evolucionista. Haveria, nessa atmosfera apocalíptica, um porvir no campo das artes? Haveria ainda arte ou este seria o seu fim? Não à toa, a geração de artistas pós-modernos americanos passou a questionar a necessidade de um conhecimento técnico para produzir suas criações. $\mathrm{Na}$ dança, essa geração trouxe para o campo das artes um corpo cotidiano, pedestre, um corpo sem referencialidade específica de uma organização prévia de como mover-se. Foi um momento em que se propalou até mesmo a ideia de uma não-arte. Sendo não-arte seria uma não-linguagem?

Pensando com Gilles Deleuze, de que as pessoas se constituem como agenciamentos coletivos de enunciação, acredito ser possível inferir que, quando abordamos o corpo, estamos diante de aspectos que envolvem sua enunciação no mundo, sua composição de gramáticas e, portanto, de linguagens. Parece-me sintomático que outros campos alheios às artes venham se interessando e se apropriando das discussões em torno do corpo e dos modos não-verbais de enunciação, algo bastante próprio da natureza das linguagens artísticas e do modo como certos artistas se expressam/se enunciam/se manifestam no mundo.

"Tremores" é o nome de um livro lançado no Brasil pelo espanhol Jorge Larrosa, em 2015. Este autor atua fortemente no campo da educação, mais especificamente na filosofia da educação. Com o subtítulo "Escritos sobre experiência", Larrosa dimensiona a experiência como aquilo que nos acontece, para o que se passa nos corpos. Porém, essa dimensão por ele defendida não se limita a uma só pessoa, a uma individualidade. Trata-se de uma dimensão que requer atenção ao outro, a uma coletividade, como explicou o autor em um congresso realizado na mesma ocasião ${ }^{2}$. Nesta obra ele traz, entre os tópicos, as palavras "respirar" e "vibrações", como que a evidenciar que há outros modos de se vivenciar uma experiência, para além de uma apreensão racional e verbal do mundo.

Ao citar o Manifesto Surrealista, de 1924, o autor lembra de uma frase na qual André Breton escreve que a experiência está confinada numa jaula, dando voltas em torno de si. Ao que diz Larrosa:

A suspeita, naturalmente, é que nossa experiência do educativo só nos acontece mediada ou enquadrada ou enjaulada pelas operações de categorização, de tematização, de ordenação, de desierarquização, de abstração, etc., que constituem as lógicas de nossos saberes e de nossas práticas. Porém há algo, seja isso o que for, que está fora da jaula e não podemos senti-lo, ou dizê-lo, ou pensá-lo, a partir de uma experiência enjaulada. Talvez sejamos nós mesmos os que damos voltas e mais voltas sobre nós mesmos, sem nenhum outro, sem nenhum exterior, sem nenhum acontecimento, sem nenhuma surpresa, sem nada distinto a nós mesmos (ou a nossas projeções, ou a nossos desejos, ou ao que já sabemos, ao que já pensamos, ao que já queremos...) que nos atinja, ou que nos aconteça, ou que nos enfrente. E talvez nossa vontade de viver tenha a ver às vezes com um desejo de tirar a experiência da jaula, de fazê-la sair, de abrila para o lado de fora, com um desejo de sairmos nós mesmos da jaula (LARROSA, 2015, p. 105-106 - grifos meus).

\footnotetext{
${ }^{2}$ Anotações do mini-curso Palabra muda. Sobre los lenguages de la experiencia y las experiencias del lenguage, ministrado por Jorge Larrosa no II Seminário Internacional de Filosofia, Poética e Educação, com o tema Habitar poeticamente a educação, entre os dias 19 e 21 de outubro de 2015, na Universidade Federal de Juiz de Fora, Minas Gerais.
} 
Esse algo que está no exterior, que não encontra fronteiras, nem nomes e nem determinações pode ser, segundo Larrosa, associado à noção de liberdade, àquilo que libera de uma asfixia e, portanto, nos faz respirar. Estaria, então, no fora da linguagem a potência de criação, do que faz respirar a arte quando ela subverte a lógica dos corpos e nos faz ver, perceber e sentir o mundo de um modo diferente? Ver com olhos livres, como dizia Oswald de Andrade?

O autor alemão Hans Ulrich Gumbrecht, que atua no campo da literatura, tem chamado atenção dos pesquisadores em artes do corpo ao tratar, nas humanidades, da noção de produção de presença. Para ele, há algo que o sentido não consegue transmitir. Essa transmissão pede uma presença que, para o autor, está ligada àquilo que se pode experimentar fora de uma linguagem, dizendo respeito a ritmos, volumes, vibrações, sensações que não encontram nas palavras um modo de serem explicadas, constituindo uma outra sensibilidade. Os efeitos de presença, em Gumbrecht, estão relacionados às experiências vividas, às percepções físicas, àquilo que nos retira do mundo cotidiano e nos faz friccionar e deslocar situações e experiências já conhecidas, dadas, normatizadas. Estar presente, nesse aspecto, é viver uma experiência antes de qualquer possibilidade de interpretação, julgamento, controle, padronização, imagens e dramaturgias prévias (GUMBRECHT, 2010; GONÇALVES, 2016).

Antes de avançar no que Larrosa e Gumbrecht nos provocam a pensar a respeito da linguagem, gostaria de me deter no que eles parecem apontar: uma experiência sem mediação, que se dá diretamente nos corpos.

\section{Que corpo, qual arte, com que linguagem?}

Uma arte sem mediação é a proposta dos artistas plásticos brasileiros Lygia Clark e Hélio Oiticica. Ambos produziram obras para serem vestidas, atravessadas, experimentadas e sentidas, que foram colocadas no mundo entre os anos 1960 e 1980. Uma arte cujo foco não está na forma, mas naquilo que as pessoas podem viver na relação com os objetos, os quais devem, invariavelmente, serem tocados e experimentados. Tais objetos - sensoriais e relacionais, no caso de Clark; ou parangolés e instalações para entrar e ficar, no caso de Oiticica - são, por eles, perspectivados como proposições vivas e não como meros objetos manipuláveis. Ambos desejavam fazer arte fora das normas instituídas. Nunca localizaram seus trabalhos como body art ou como happening, pois diziam que ainda residia nessas formas artísticas algo de espetacular, a ser visto e apreciado, delimitando um espaço de apresentação, o que não correspondia às proposições desses artistas. Clark chegou a dizer que arte, igreja e museu são instituições que já não existem, mas as pessoas não se dão conta (GONÇALVES, 2018).

Lygia Clark propõe um "singular estado de arte sem arte" (CLARK, 1980, p. 28), portanto sem a mediação institucional. Clark e Oiticica oferecem como exercício artístico cindir com a relação dual entre sujeito e objeto, entre a arte e o público/espectador passivo, pois fazem da arte uma experiência que se dá na própria relação entre corpos, humanos e não-humanos, sem apelo imagético, simbólico, representacional. Afinal, seus objetos são feitos de materiais ordinários, igualmente sem apelos, os quais, em si, não despertam curiosidades. A obra se faz quando, na relação com o outro, os corpos se põem a inventar possibilidades de usos, de movimentos, de danças, de imaginação, em suma, de criação - e esta se dá na chave de uma cocriação, sempre compartilhada, sempre em ato.

Tratam-se de proposições que afetam diretamente os corpos, por um viés sensorial. $\mathrm{O}$ desejo não é que os corpos identifiquem, categorizem, enquadrem - enjaulem, para lembrar a provocação de Larrosa - os objetos e/ou a experiência. Ao mobilizar as sensações, tais propostas não estimulam apenas um sentir a pele, o seu calor e o que está na superfície de inscrição dos corpos. Os artistas querem que suas peças se confundam com a pele e com as 
sensações, para acionar uma linguagem pré-verbal. Portanto, uma linguagem relativamente livre de interpretações, julgamentos, finalidades, que chegue aos corpos antes que eles possam ser capturados por um mapa prévio de sensações e percepções de mundo, deslocando, pela relação corporal, os sentidos e abrindo os corpos a outras possibilidades sensoriais e perceptivas, portanto outros modos de ver, perceber e sentir o mundo.

Trata-se de gerar sensações das quais não se tem registro ou de sincronizar, em movimento, vários registros nunca antes combinados, provocando uma convulsão sensorial. Esses são destaques do pesquisador do movimento Hubert Godard (2006) a respeito da obra de Lygia Clark, em entrevista a Suely Rolnik publicada no catálogo da exposição da artista na Pinacoteca de São Paulo, em 2006, intitulado Lygia Clark, da obra ao acontecimento. Somos o molde. A você cabe o sopro. Clark nos convida, segundo Godard, a um modo de mover os filtros de uma sensorialidade marcada pela linguagem e pela percepção enquadrada e objetificada de mundo. Ao propor uma experimentação que produza um mergulho subjetivo pela perda de noções gravitacionais e por ativar camadas de sensações menos marcadas pela linguagem, o pesquisador diz que o trabalho da artista, com os objetos relacionais, recoloca em movimento o imaginário, permitindo ao corpo operar por ele mesmo, rompendo com monopólio de um sentido sobre o outro, com a neurose da percepção, nas dinâmicas da relação de si com o mundo.

O trabalho sobre a sensorialidade permite abrir e reinventar os volumes do ar que nós nos autorizamos, de pacificar o espaço para que o corpo encontre aí o seu lugar. [...] Os sentidos agem entre si, assim, sem parar, e há frequentemente conflitos de informação de um sentido ao outro (GODARD, 2006, p. 76).

E aqui vale lembrar o sub-título da obra de Gumbrecht: "o que o sentido não consegue transmitir" (2010). Para o autor, é preciso oscilar entre os efeitos de presença e os efeitos se sentido, ao que ele pontua: "só os efeitos de presença apelam aos sentidos" (GUMBRECHT, 2010, p. 15). O que me faz pensar na frase de Suely Rolnik sobre o desafio das sensações aos corpos: "Quando uma sensação se produz, ela não é situável no mapa de sentidos de que dispomos e, por isso, nos estranha" (ROLNIK, 2002, p. 3). Portanto, a dimensão de uma experiência vivida com o corpo, pelo viés sensorial, evoca outros rearrajos de sentidos consequentemente de interpretações, julgamentos e, até mesmo, categorizações - que nos fazem variar e compor outros modos de ver, perceber e sentir o mundo.

Lygia Clark e Hélio Oiticica seguem nos provocando, na contemporaneidade, pois é desejo deles que cada um de nós possa desenquadrar a percepção. Acrescento, ainda, com Larrosa, que ambos nos alertam para os riscos de um enjaulamento de nossos mapas de sentidos, de nossa elaboração de linguagem. Afinal, ambos propõem o fim do quadro como suporte da arte, ao que se segue também a necessidade de desenquadrar o corpo e, com ele, descolonizar a nossa percepção. Mas isso não é tarefa das mais fáceis, pois ainda é comum entendermos os corpos, sobretudo dos artistas, como suportes para as obras de arte, reiterando uma lógica que separa sujeito e objeto, que dicotomiza a relação entre artista e público, que separa sensação e razão, sentir e pensar.

Essa relação tem um demarcador histórico importante: o projeto de modernidade instaurado a partir do século XV. Numa retomada do pensamento platônico, que defende um mundo ideal descolado do mundo real, as sensações foram dicotomizadas em relação à razão e esta foi enfatizada e enaltecida, num longo processo de cisão entre corpo e mente. Nesse período, o espaço foi recortado em quadros e geometrizado, o tempo aprisionado nos relógios e o movimento restringido, numa tentativa de afirmar certezas definitivas, manter os corpos afastados dos riscos e a natureza dominada e subordinada pelos humanos, especialmente os ocidentais e europeus, antropocêntricos, que se tomaram medida de todas as coisas. O projeto 
de modernidade, tal como descrito por Marila Velloso (2011), cindiu sujeito de objeto, pessoa de natureza, homens de animais, pensar de sentir, quem observa de quem é observado.

Tal recorte sensorial instaurou um mundo mediado por modelos calcados na objetividade e na pressuposição de uma realidade única e universal, no qual as pessoas passaram a vivenciálo como algo fora de si, introjetando regras, códigos, modos de agir. Até mesmo a noção, por vezes ainda viva, de que o corpo é algo que se "tem" e se "carrega" é tributário desse projeto. Restringidas as possibilidades da percepção e da sensorialidade, o que se vê é um processo no qual as instituições passaram a controlar e a deter os desejos, instintos, sensações, emoções dos corpos para fazê-los dóceis, portanto, pacificados. Inclusive, a separação entre o sagrado e o profano é o legado de uma tradição de pensamento que a arte herdou (GONÇALVES, 2018). Por consequência, o sistema artístico tinha modelos pré-concebidos que sinalizavam "o que é" e "o que não" é digno de ser considerado como arte.

Para o crítico de arte Brian O’Doherty (2002), as obras do Modernismo, ao proporem modos de descolonizar a percepção, geraram uma angústia sensorial por desafiarem os modelos perceptivos de sua época. Os artistas deram vazão a poéticas que colocaram em questão a própria constituição da linguagem artística. As cisões de tempo, espaço e ação do projeto moderno, iniciado no século $\mathrm{XV}$, são revistas. $\mathrm{O}$ corpo, no século $\mathrm{XX}$, passa a ser um laboratório da percepção e reconecta a matéria sensível à pensante, descola e confunde formas, conteúdos e fronteiras. A própria noção de corpo é desafiada e ele começa a ser experimentado como aberto, permeável, poroso. No entanto, quebrar com um tipo de registro de sensorialidade requer atenção. Não basta gerar uma angústia sensorial, desestabilizar os padrões, pois nesse movimento de fissuras outras referências podem se estabelecer, como por exemplo a voz do crítico ou curador de arte a dizer o que deve ou não ser valorizado, pontua O'Doherty.

Como então descolonizar a percepção, desenjaular a experiência com as artes, libertar a linguagem artística de modelos fechados em si, auto-referentes? Será que a dança pode oferecer pistas de um ponto de encontro ou ser uma encruzilhada interessante para desenquadrar as percepções e produzir linguagens artísticas mais porosas, mais respiradas, uma vez que o corpo está tão implicado em seu fazer?

\section{Fricções, transbordamentos e composições de linguagem em arte}

Vejo com curiosidade o fato de que, como mostram registros em torno das produções das vanguardas modernistas, ter sido comum que os artistas e os filósofos da virada dos séculos XIX para o XX nominassem como dança manifestações que escapassem de uma definição possível. Isso aconteceu, entre outros, com o ator e diretor teatral Antonin Artaud, sobretudo a partir das experiências corporais com a tribo indígena mexicana do Tarahumaras, na década de 1930, e também com o filósofo Friedrich Nietzsche, o mesmo que disse ser capaz de acreditar num deus que dançasse. $\mathrm{O}$ termo dança era usado por eles para referir-se a algo que fazia mover os sentidos de uma manifestação artística, de um pensamento em criação.

São situações que implicam uma vivência de caráter desconhecido e, ao mesmo tempo, de inquietação e desassossego ligados às afecções mais diretas do corpo, como grunhidos, sussurros, salivas, glossolalias - aspectos corporais descolados de categorizações, julgamentos, interpretações, enquadramentos - jaulas - para desafiar criações que possam ser menos marcadas de códigos e colonizações da percepção. É nesse sentido que Lygia Clark e Hélio Oiticica acreditam numa arte que somente se realiza na experimentação, em ato, na fabulação dos corpos. A ênfase, portanto, dessa arte não está nos aspectos visual, figurativo, formalizado, embora esses registros também se efetuem (GONÇALVES, 2018). 
Porém, nem toda produção artística está aberta a experimentações, a possibilidades de composições permeáveis e porosas. Assim, como pensar o termo "linguagem" ao tratar da dança/arte em sua potência artística na contemporaneidade? Marco traços de diferenças entre uma dança/arte (auto-)referente, fechada em determinados códigos e componentes simbólicos, e uma dança/arte-devir ${ }^{3}$ em sua potência de abrir o sentido da experiência ao novo, ao impensado, ao imprevisto. Trata-se, aqui, de propor uma mudança de lógica na percepção da arte em direção à potência inventiva da vida, em contraponto à arte como modelo. Isto implica em transitar diferentemente entre a lógica da representação, dos modelos ideais, da transcendência, repetição, reprodução, e a lógica da diferença, singularização e criação.

Se, ao ponderar em que condições dança/arte é linguagem, é possível seguir em direção à ideia de uma gramática, o seu domínio implica na possibilidade de um bailarino - ou aluno, no caso de um contexto pedagógico - deixar a condição de analfabeto para a de alfabetizado em dança/arte. Ao compor uma obra é como se o artista "escrevesse" um poema, um conto, um romance, cuja lógica é entendida e pode ser "verbalizada em palavras", ganhando um significado - um território fixo, uma finalidade. Para isso, deve aprender os elementos que configuram uma linguagem em arte.

No caso da dança, tais elementos podem configurar-se com as ações (partes do corpo que se movem), as dinâmicas (como o corpo se move), o intérprete (quem se move), numa relação com a paisagem sonora e o espaço, conforme sistematiza o artista e pesquisador da dança Rudolf von Laban. São aspectos que compõem o que ele denominou estudo do movimento e que integram a coreologia - estudo da dança ou ciência da dança (MARQUES, 2010). Saber girar, saltar, utilizar os níveis espaciais e se deslocar em diferentes direções são alguns exemplos de elementos da dança a serem conhecidos e dominados.

Em geral, quando se trata de uma dança específica, como o flamenco, o balé, a dança de rua, o samba, o que percebemos é que cada gênero implica uma combinação já dada de elementos da dança que constituem seus códigos, com referentes fixos, com sua identidade quase sempre fechada em si. Na medida em que essa compreensão segue a lógica da representação, do mundo simbólico, o bailarino e/ou aluno, antes destituídos de conhecimento (formação/informação) e, portanto, analfabetos, são percebidos como sujeitos autônomos, emancipados, conscientes quando sabem se comunicar e se fazem entender com a linguagem da dança, tornando-se alfabetizados (GONÇALVES, 2010). O sentido da dança, no entanto, fecha-se em um significado (conteúdo) e em um significante (forma), aos quais cabem a pergunta: "o que isso quer dizer?" (DELEUZE, 1992, p. 33).

$\mathrm{O}$ artista e crítico de arte Fernando Cocchiarale, na obra Quem tem medo de arte contemporânea?, faz uma observação interessante a respeito da relação do público com a arte. Segundo ele, há uma tendência do grande público em gostar de obras nas quais eles possam aplicar o verbo "entender", limitando a amplitude das possibilidades de uma experiência artística. "Como as pessoas têm medo de sentir, elas entendem, reduzem sua relação ao ato inteligível” (COCCHIARALE, 2006, p. 14). É interessante notar que Laban, entretanto, na primeira metade do século XX, já pensava a dança independente da palavra e da finalidade dada a priori, chegando a associá-la ao ato de brincar, da experimentação de situações inimagináveis. Para ele, pensar por movimentos, ou pensamento-movimento, está relacionado a um "conjunto de impressões de acontecimentos" para o qual não se tem uma nomenclatura adequada,

\footnotetext{
${ }^{3}$ Devir é, segundo Deleuze: “jamais imitar, nem fazer como, nem ajustar-se a um modelo, seja ele de justiça ou verdade. Não há um termo de onde se parte, nem um ao qual se chega ou se deve chegar. Tampouco dois termos se trocam. A questão "o que você está se tornando" é particularmente estúpida. Pois à medida que alguém se torna, o que ela se torna muda tanto quanto ele próprio. Os devires não são fenômenos de imitação, nem de assimilação, mas de dupla captura, de evolução não-paralela, núpcias entre dois reinos” (DELEUZE; PARNET, 1998, p. 10).
} 
constituem experiências que fazem calar e são inexprimíveis de outro modo. Esse tipo de pensamento, para o bailarino, aperfeiçoa-se no fazer e no dançar.

Quando nos movimentamos, nós criamos relacionamentos mutáveis com alguma coisa. [...] O uso exclusivo de movimentos com um significado fixo jamais resultará num trabalho de arte, pois é precisamente a combinação incomum de movimentos que os torna interessantes para o público. [...] o artista e o bailarino [...] basear-se-ão mais no sentido do movimento do que numa análise consciente do mesmo. [...] ideias e emoções que ultrapassam os pensamentos passíveis de serem expressos em palavras (LABAN, 1978, p. 109-153).

Para Félix Guattari, parceiro de Deleuze, o "mundo das representações vai ser apenas o mundo dos significantes, concebidos segundo teorias linguísticas que reduzem a linguagem a sistemas de oposições distintivas" (GUATTARI; ROLNIK, 2005, p. 250) e, portanto, não nos serve para nada, uma vez que a linguagem interessa enquanto intensidades, fluxos, processos, coisas que não querem dizer nada e que fazem passar algo que se dá na relação de corpos, naquilo que faz silenciar, portanto na dimensão da experiência e do vivido, conforme Larrosa e Gumbrecht. Para Guattari, a vida pode ser inventada mesmo quando todas as imagens são produzidas de antemão, pois interessa o que será feito com elas.

O principal é livrar-se dessa espécie de redundância, de serialidade, de produção em série da subjetividade, de solicitação permanente a voltar ao mesmo ponto. Penso que existem múltiplos componentes de expressão que não passam pela linguagem tal como é fabricada pela escola, pela universidade, pela mídia e por todas as formas de poder. A expressão do corpo, a expressão da graça, a dança, o riso, a vontade de mudar o mundo, de circular, de codificar as coisas de outro modo, são linguagens que não se reduzem a pulsões quantitativas, globais. Constituem a diferença (GUATTARI; ROLNIK, 2005, p. 63-334).

Deleuze, em referência a Michel Foucault, argumenta ser preciso abrir as palavras, rachálas por dentro para que elas liberem vetores imanentes, devires e invenção (DELEUZE, 1992). No que podemos pensar em rachar os códigos da dança/arte, desmontá-los, reordená-los, criar com eles blocos de sensações, novas maneiras de sentir e compor arte. Seguindo, então, em direção à dança/arte como devir, que não seja finalidade nem mediação (entretenimento, lazer, ocupação do tempo ocioso), mas encontro, agenciamento, experiência, é possível perceber que Laban propõe um domínio da linguagem artística no qual os elementos da coreologia não sejam estáticos e imutáveis. A coreologia pode ser entendida, nos termos de Deleuze e Guattari, como um agenciamento coletivo de enunciação e, como tal, é, ao mesmo tempo, um território esburacado, poroso, onde se produzem significados e referentes, porém provisórios, constituídos por pontas de desterritorialização, no iminente risco de se gerar descodificações e aberturas a novos sentidos e agenciamentos. Portanto, lugar da criação.

Sendo assim, não é possível traçar correlações tão diretas entre a linguagem artística e a linguagem verbal, em seus modos operativos. O risco é de encontrarmos um analfabeto funcional nas artes. Aquele que acredita saber manejar a língua, pois sabe dela as formas, os códigos, as técnicas e como repetir signos, sem saber ao certo o porquê de determinadas combinações, escolhas e sem saber fazer o pensamento-corpo dançar, fabular, inventar, poetizar. Talvez essa seja minha desconfiança em relação ao termo "linguagem" para tratar do universo das artes, bem como talvez seja o que Larrosa e Gumbrecht estejam nos mostrando, quando dizem que há um fora da linguagem que atravessa os corpos de um modo diferente. 
Afinal, se nossa percepção foi enquadrada e se percebemos o mundo fora de nós e, para fazer parte dele, introjetamos regras, códigos e modos de agir, para escapar dessa jaula é preciso vazar, romper, fissurar, friccionar. No entanto, é também preciso destacar, que até mesmo a linguagem verbal, quando avança no sentido da invenção poética, requer um manejo da gramática que faz não só as palavras, como o sentido de organização gramatical e semântico serem quebrados por dentro, descodificados, rearranjados de um modo inusitado.

A questão que me parece interessante é estar na via corporal, sensorial e física o ponto de articulação entre as linguagens, sejam elas verbais ou não, quando elas, as linguagens, desejam liberdade, respiração, experiências que modificam as pessoas em sua relação consigo e com o mundo para além dos roteiros. No tópico "Vibrações" de seu livro, Larrosa (2015) enuncia que as palavras traçam rastros, vibram no ar até tocarem os outros. "O destino da palavra é de se desintegrar quando chega a tocar o que é mais sólido do que ela: a carne. [...] A palavra se encarna, seu destino é encarnar-se" (LARROSA, 2015, p. 113). Acredito que Larrosa esteja dizendo que a palavra, em si, não é o protagonista de uma enunciação, mas a vibração por ela produzida no contato com os corpos. A linguagem, assim percebida, está na ordem do imponderável, do que pode ser movido, mobilizado e suscitado em nós.

José Gil cita o exemplo de um xamã que, num processo de cura, por exemplo, é responsável por fornecer ao doente uma "linguagem" na qual são expressos certos estados do corpo não formulados e não formuláveis de outra maneira, os quais desbloqueiam processos fisiológicos. Trata-se de uma "linguagem" vivida no corpo e que é "incodificável". Um corpo, nessas condições, está pleno da vibração do mundo e não de distingue dela. São forças em movimento. Há qualquer coisa de intraduzível, um segredo. Em suma, um corpo que precede e prescinde de uma linguagem formalizada, sendo um "campo privilegiado das práticas mágicas, da leitura dos presságios" (GIL, 1995, p. 224).

Há toda uma gramática sensorial relativa aos corpos que transbordam os limites que a ele sejam impostos. É dessa linguagem que tratam artistas que rompem com as mediações, como Lygia Clark, Hélio Oiticica, Antonin Artaud, entre outros. É dessa linguagem que tratam autores como Nietzsche, Larrosa e Gumbrecht. Tem-se aqui um desafio que me parece imprescindível para a educação em artes na contemporaneidade: uma relação com as gramáticas sensoriais, com uma subjetividade oscilando entre os efeitos de presença e os efeitos de sentido que impregne a vida de experiências artísticas. Uma linguagem que atue no paradoxo do dentro e do fora de si em articulação com o mundo.

\section{Referências}

CLARK, L. Lygia Clark. Textos de Lygia Clark, Ferreira Gullar e Mário Pedrosa. Rio de Janeiro: FUNARTE, 1980.

COCCHIARALE, F. Quem tem medo de arte contemporânea? Recife: Fundação Joaquim Nabuco - Editora Massangana, 2006.

DELEUZE, G. Conversações, 1972-1990. São Paulo: Ed. 34, 1992. . Francis Bacon: lógica da sensação. Rio de Janeiro: Zahar, 2007.

DELEUZE, G.; PARNET, C. Diálogos. Tradução de Eloísa Araújo Ribeiro. São Paulo: Editora Escuta, 1998. 
GIL, J. Corpo. In: GIL, F. (Org.). Enciclopédia Einaudi. Soma/psique - Corpo. Lisboa: Imprensa Nacional - Casa da Moeda, 1995. 32v. p. 201-266.

. Movimento total: o corpo e a dança. Tradução de Miguel Serras Pereira. São Paulo: Iluminuras, 2004.

GODARD, H. Olhar cego. Entrevista com Hubert Godard. In: ROLNIK, S. (Org.). Lygia Clark, da obra ao acontecimento. Somos o molde. A você cabe o sopro. São Paulo: Pinacoteca do Estado, 2006. p. 73-79.

GONÇALVES, T. Coreografias da política cultural: dancituras da diferença na Escola de Dança de Paracuru. 2010. Dissertação (Mestrado em Políticas Públicas e Sociedade) Departamento de Sociologia, Universidade Estadual do Ceará, Fortaleza, 2010.

Objeto descontínuo, criação de sensorialidades em ato por Gustavo Sol. Revista Croma, Estudos Artísticos, Lisboa/Portugal, v. 4, n. 8, 104-111, jul.-dez. 2016. Disponível em: <http://croma.fba.ul.pt/C_v4_iss8.pdf $>$. Acesso em: 17 nov. 2019.

Sensorialidades antropofágicas: saberes do sul na dança contemporânea. 2018. Tese (Doutorado em Artes da Cena) - Instituto de Artes, Universidade Estadual de Campinas, São Paulo, 2018.

GUATTARI, F.; ROLNIK, S. Micropolítica: cartografias do desejo. Petrópolis: Vozes, 2005.

GUMBRECHT, H. U. Produção de presença: o que o sentido não consegue transmitir. Tradução de Ana Isabel Soares. Rio de Janeiro: Contraponto: Ed-PUC-Rio, 2010.

LABAN, R. Domínio do movimento. Tradução de Anna Maria Barros De Vecchi e Maria Silvia Mourão Netto. São Paulo: Summus, 1978.

LARROSA, J. Tremores: escritos sobre experiência. Tradução de Cristina Antunes e João Wanderley Geraldi. Belo Horizonte: Autêntica Editora, 2015.

MARQUES, I. Linguagem da dança: arte e ensino. São Paulo: Digitexto, 2010.

O'DOHERTY, B. No interior do cubo branco: a ideologia do espaço da arte. Tradução de Carlos S. Mendes Rosa. São Paulo: Martins Fontes, 2002.

ROLNIK, S. (2002). Subjetividade em obra. Lygia Clark, artista contemporânea. Disponível em: $\langle$ http://www.pucsp.br/nucleodesubjetividade/Textos/SUELY/Subjemobra.pdf $>$. Acesso em: 21 nov. 2019.

VELLOSO, M. Modos de ver e vivenciar o mundo: invertendo as lentes do ensino da dança. In: WOSNIAK, C.; MARINHO, N. (Org.), O avesso do avesso do corpo: educação somática como práxis. Joinville: Nova Letra, 2011. p. 133-146. 


\section{Sobre a autora}

Professora Adjunta na graduação em Dança da Universidade Federal do Ceará (UFC). Doutora em Dança e em Artes da Cena, respectivamente, pela Universidade de Lisboa (ULisboa) e pela Universidade Estadual de Campinas (UNICAMP), onde graduou-se em Dança. Realiza pesquisa junto ao Instituto de Etnomusicologia - Centro de Estudos em Música e Dança (INETMD), no Projeto TEPe - Technologically Expanded Performance, vinculado à Fundação para a Ciência e a Tecnologia (FCT) de Portugal.

E-mail: thgoncalves@ hotmail.com. 